
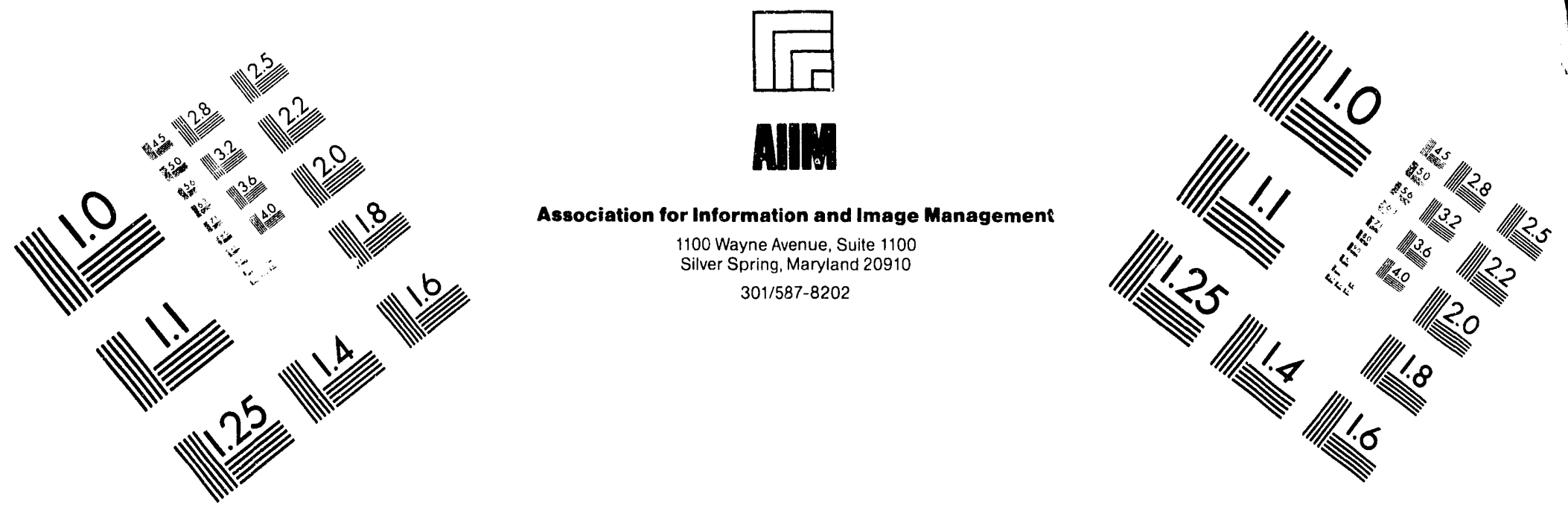

Centimeter

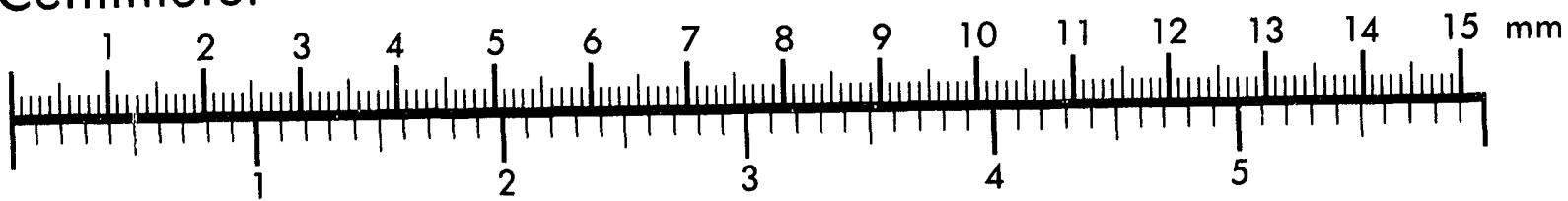
Inches
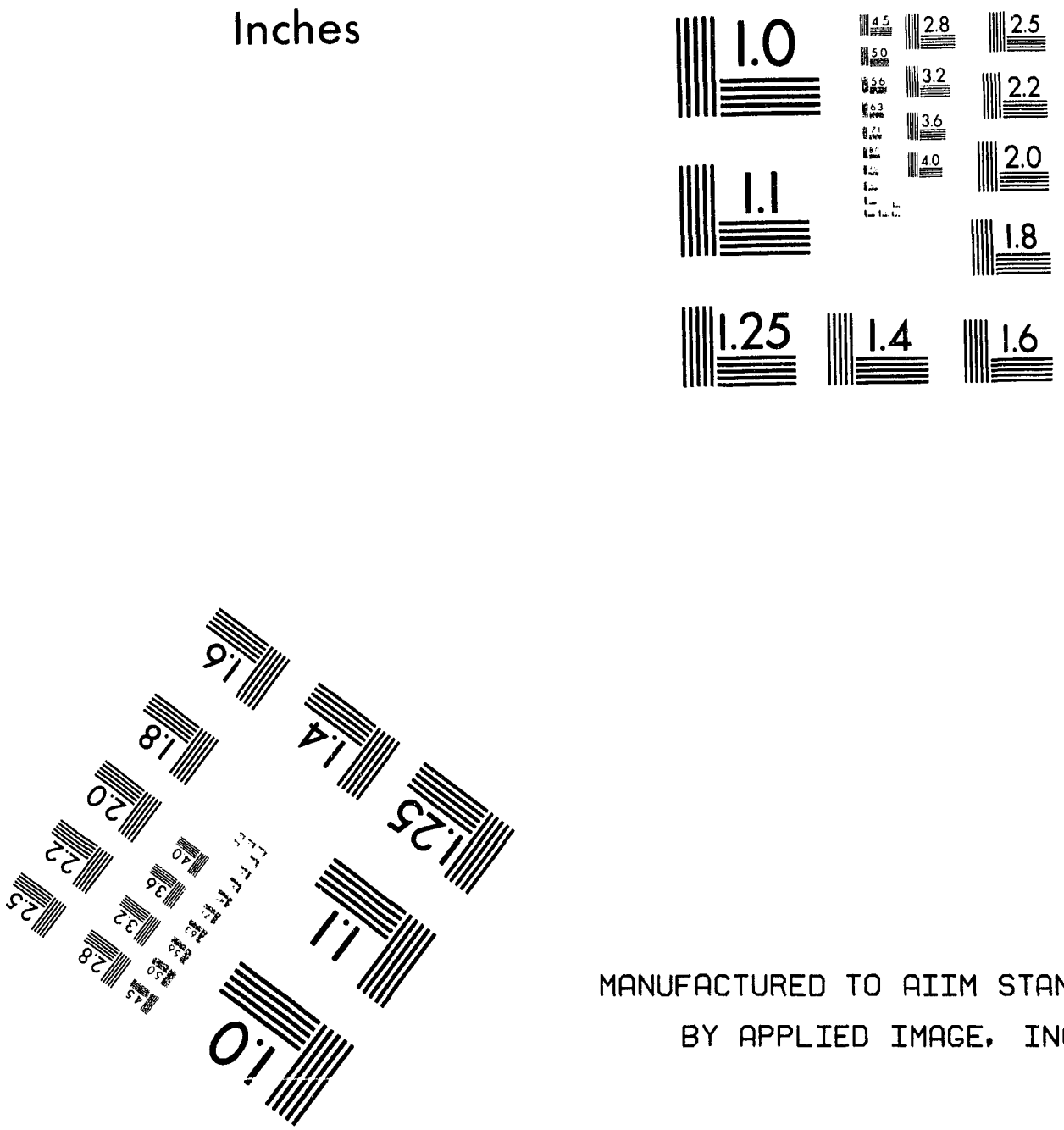

MANUFACTURED TO AIIM STANDARDS

BY APPLIED IMAGE, INC.

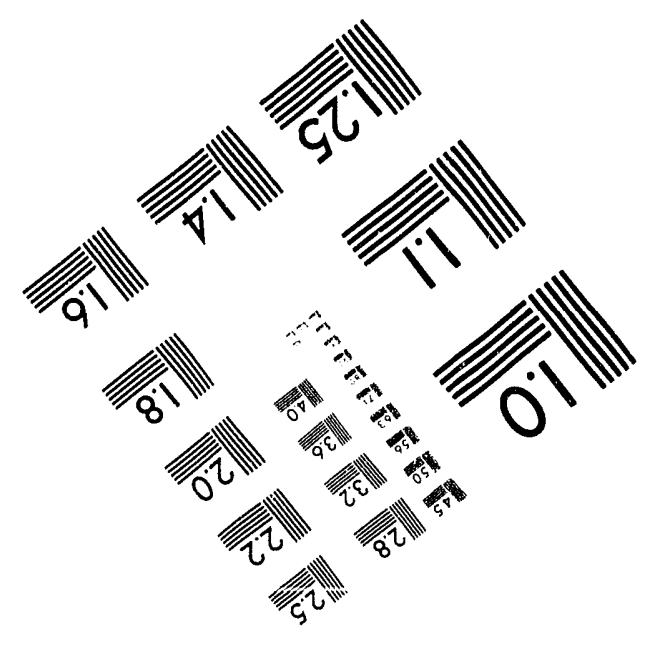



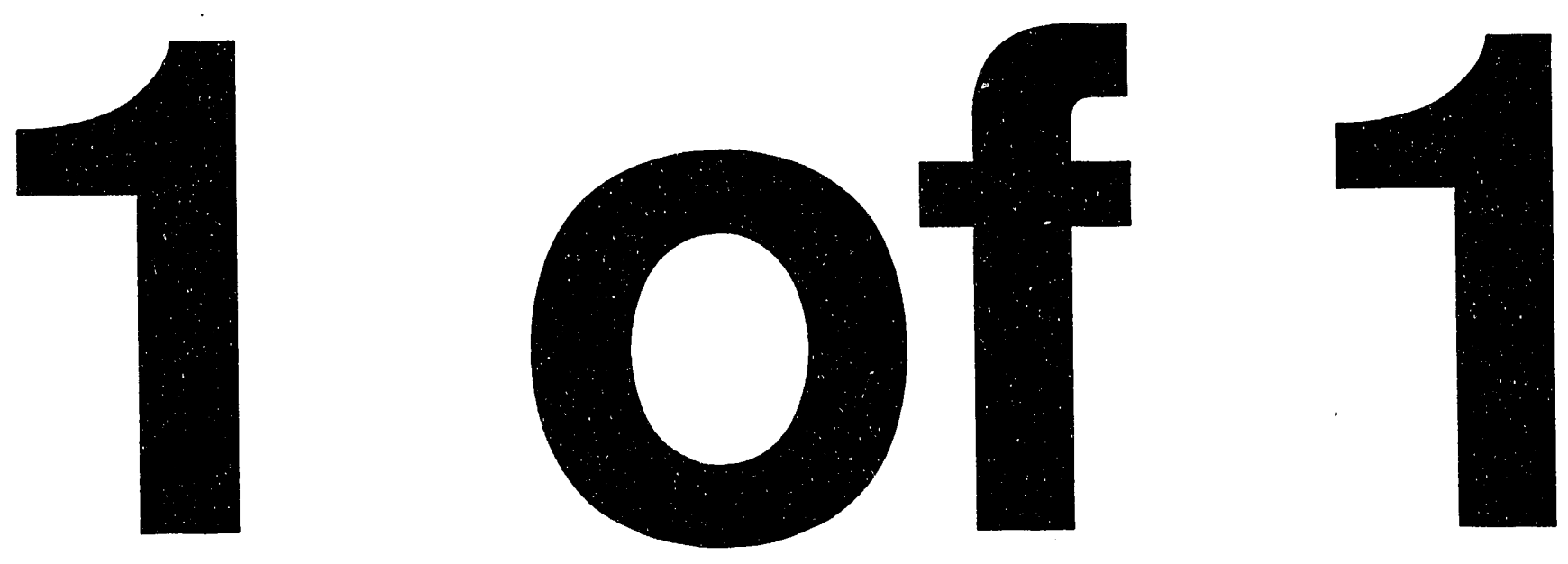


\title{
Review of Disposal Systems, Inc., Proposed Method for the Determination of Health Based Limits for Waste Substances Not Covered in UIC Guidance No. 71
}

by

\author{
John A. Apps \\ Earth Sciences Division \\ Lawrence Berkeley Laboratory \\ University of California \\ Berkeley, California 94720 USA
}

January 26, 1993

Project Officer:

Robert E. Smith

Underground Injection Control Branch

Office of Drinking Water,

U.S. Environmental Protection Agency

Washington, DC 20460

This work was supported by the Underground Injection Control Branch, Office of Drinking Water, U.S.

Environmental Protection Agency, through U.S. Department of Energy Contract No. DE-AC03-76SF00098 


\section{CONTENTS}

Section Page

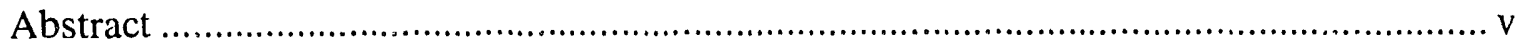

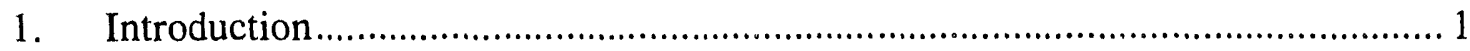

2. Procedures Adopted by Envirotech, Inc., in the Preparation of Table 1............. 2

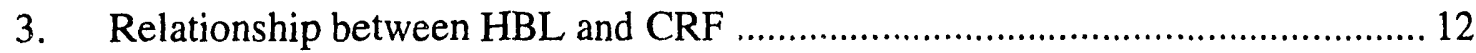

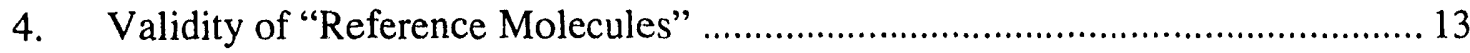

5. Upgrading Support document UIC Guidance No. 71 .................................... 14

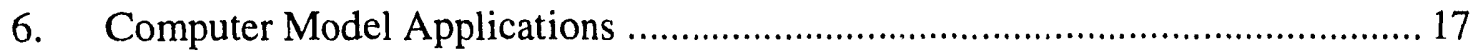

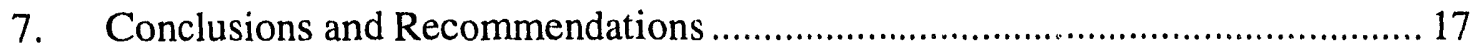

Figures

Figure $\quad$ Page

1. Logic Chart for the Selection of HBLs ................................................... 3

Tables

Table $\quad \underline{\text { Page }}$

1. Compounds Not Listed in Appendix VIII ........................................................ 5

2. Compounds with Lower SW-846 Detection Limits Than Those

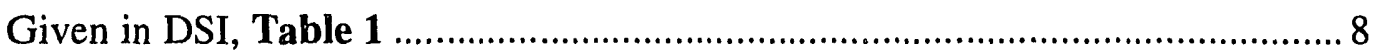

3. Compounds with Higher SW-846 Detection Limits Than Those

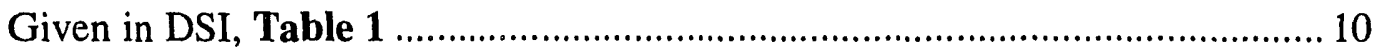

4. Table A. Applicable Health Based Limits for "No Migration" Petitions ............ 15 


\title{
Review of Disposal Systems, Inc., Proposed Method for the Determination of Health Based Limits for "Vaste Substances Not Covered in UIC Guidance No. 71
}

\author{
John A. Apps \\ Earth Sciences Division \\ Lawrence Berkeley Laboratory \\ University of California \\ Berkeley, California 94720 USA
}

\begin{abstract}
The Underground Injection Control Branch of the Office of Drinking Water, U.S. Environmental Protection Agency requested evaluation of a document submitted by Disposal Systems, Incorporated (DSI), in which health based limits (HBLs) were established for 442 hazardous compounds listed in 40 CFR 261, Appendix VIII and 40 CFR 264, Appendix IX. The contractor was asked to review the document, evaluate the proposed methods for assigning HBLs, and determine whether the relationship established between HBLs and concentration reduction factors is valid. He was also asked to determine the suitability of the use of "reference molecules" as a substitute for those compounds for which no data allows specification of HBLs and evaluate whether DSI's approach could be used to modify and upgrade UIC Guidance No. 71. Finally, the feasibility of computer model simulations was to be considered if complex and varied mixes of compounds were to be injected.

The approach adopted in DSI's submission is generally satisfactory, but a number of irregularities and inconsistences should be resolved before acceptance. The use of reference molecules is satisfactory, but might not be necessary. The principles adopted by DSI can be applied, with minor modifications, to updating and revising UIC Guidance No. 71. Revision of UIC Guidance No. 71 is in any case desirable, to remove ambiguities and make it easier for petitioners to use in preparing their submissions.
\end{abstract}




\section{Introduction}

This report was prepared in response to a request from Robert E. Smith of the Underground Injection Control Branch of the Office of Drinking Water, U.S. Environmental Protection Agency (EPA) to evaluate a document prepared by Envirocorp, Inc. for the GNI Group, Inc., Disposal Systems Incorporated, (DSI) The document, entitled "Waste Components, Health-Based Limits, and Concentration Reduction Factors" was submitted to EPA, Region 6, in support of a UIC no-migration petition. A major part of the submission is Table 1 entitled "40 CFR 261 Appendix VIII and 40 CFR 264 Appendix IX Waste Components and Concentration Reduction Factors," herein after referenced as Table 1, in bold, to distinguish it from tables incorporated in this report.

DSI followed systematic procedures in identifying health based limits (HBLs) or the lowest identifiable detection limits for all compounds listed in 40 CFR 261, Appendix VIII, and 40 CFR 264, Appendix IX. For over one quarter of the compounds listed, however, no HBL or detection limit is given in any EPA publication. DSI chose to overcome this problem through selection of so called "reference molecules," possessing similar structures and functional group(s) to those of the hazardous compounds, but with known HBLs or analytical detection limits.

The contractor was requested to perform the following tasks:

- Review the document and follow up with a thorough evaluation of the proposed methods for assigning HBLs for each 40 CFR 261, Appendix VIII compound.

- Determine whether the relationship as established by DSI between the HBLs for each constituent and concentration reduction factor is valid.

- Determine the validity and suitability of the use of a "reference molecule" as a substitute for those compounds not found to have data in any of the documents mentioned above.

- Evaluate whether the findings from DSI's effort (Table 1) would be useful in modifying or upgrading the support documents to UIC Guidance No. 71.

- Determine the feasibility and application of computer model simulation to this complex and varied organic and inorganic mix of compounds if they were injected. 


\section{Procedures Adopted by Envirotech, Ins. in the Preparation of Table 1.}

Table 1 is part of a more extensive submission by DSI for a no migration petition for a specific site. The table consists of 11 columns.

(0) No.

(1) Common Name (Reference Molecule)

(2) Chemical Abstracts No.

(3) EPA Hazardous Waste No.

(4) Solubility (mg.L-1)

(5) Average Maximum Wellhead Concentration Limit, $\mathrm{C}_{0}\left(\mathrm{mg} . \mathrm{L}^{-1}\right)$

(6) Specified Health-Based Limit, $\mathrm{C}_{\mathrm{HBL}}\left(\mathrm{mg} . \mathrm{L}^{-1}\right)$

(7) Source Guidance Document No. 71 Table

(8) Analytical Method

(9) Detection Limit, $\mathrm{C}_{\mathrm{HBL}}$ (mg.L $\mathrm{L}^{-1}$ )

(10) Concentration Reduction Factor, $\mathrm{C}_{\mathrm{HBL}} / \mathrm{C}_{\mathrm{O}}$.

The Table lists 442 compounds, most of which have been drawn from 40 CFR 261, Appendix VIII. Compounds are listed in alphabetical order and numbered from 1-442 inclusive. Columns (1)-(4) are self explanatory. Columns (6) and (9) require further comment.

For all compounds listed, a specific health-based limit (HBL) was sought using UIC Guidance No. 71, Tables A-D. If a HBL was identified, it was incorporated in Column (6) and the Guidance No. 71 table identified. If no HBL was listed, then an analytical detection limit for that compound was sought according to a systematic screening procedure, as illustrated by the logic chart in Figure 1. The final step of this procedure was to identify for each substance its detection limit using the most sensitive analytical method given in the Third Edition of SW-846, and to report that detection limit in Column (9) along with the analytical method in Column (8).

Column (5) gives a worst case value for $\mathrm{C}_{0}$, set as high as possible in order to ensure that the legal operation of the disposal facility is not jeopardized by waste substance well head concentrations higher than would be approved by EPA during the petition review process. Column (10) gives the Concentration Reduction Factor (CRF) where 


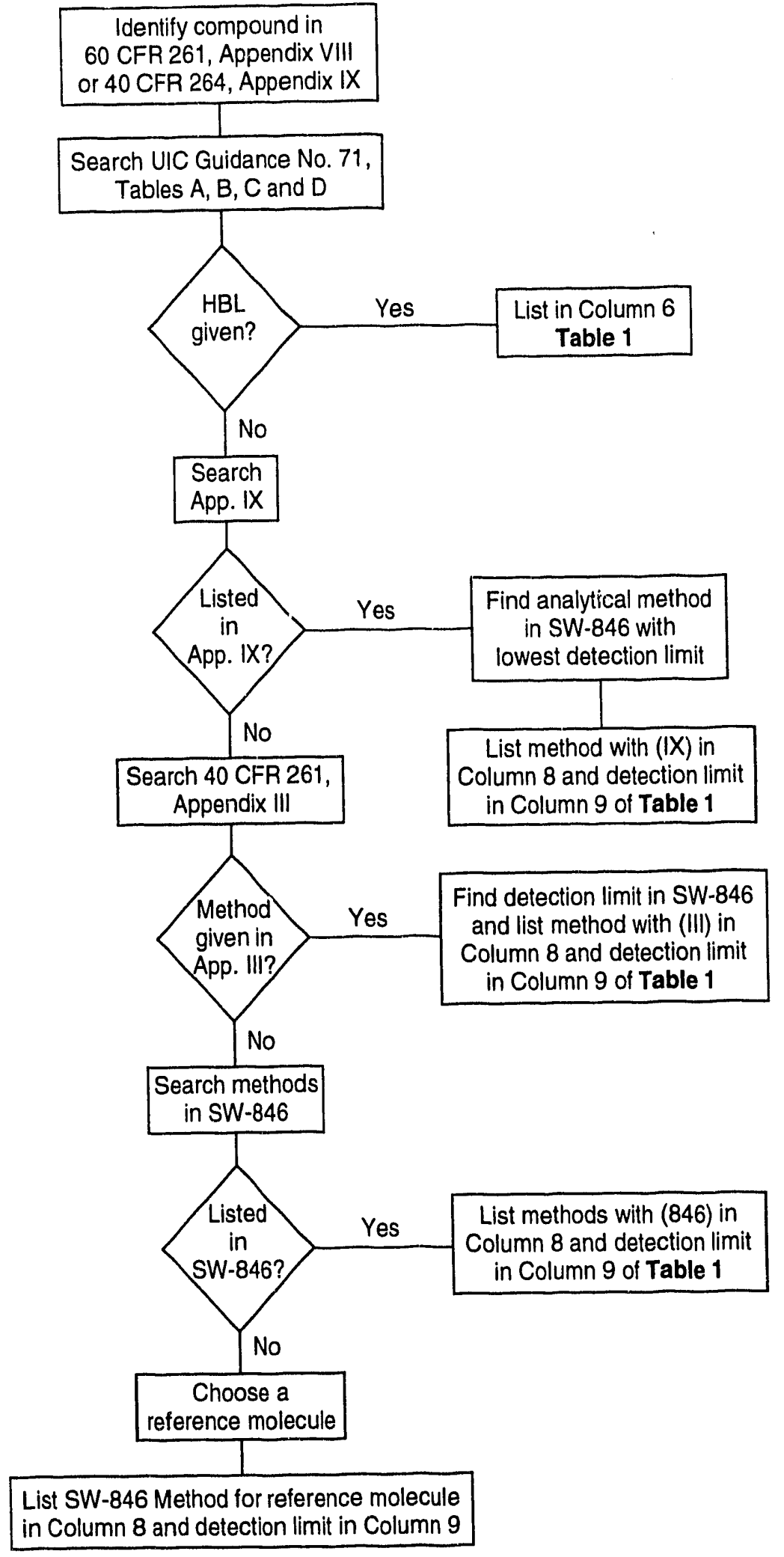

Figure 1. Logic chart for selection of HBLs. 


$$
\mathrm{CRF}=\frac{\mathrm{C}_{\mathrm{HBL}}}{\mathrm{C}_{\mathrm{o}}}
$$

For the disposal site in question, the minimum CRF was calculated to be $7 \times 10^{-11}$, based on an assigned value of $7 \times 10^{-5}$ for $\mathrm{HBL}$ and a $100 \%$ waste constituent concentration (106 $\left.\mathrm{mg} \cdot \mathrm{L}^{-1}\right)$.

Column (4), the substance solubility (in water?) permits a quick comparison to be made between that maximum acceptable concentration, $\mathrm{C}_{0}$, and the maximum realistic concentration achievable in the injection zone (subject to certain provisions). It is therefore a convenient reference guide to identifying those constituents requiring more careful monitoring.

The reviewer checked to ensure that all hazardous constituents listed in 40 CFR 261 Appendix VIII had been incorporated in DSI's Table 1. All compounds in 40 CFR 261 Appendix VIII are listed except phenylenediamine and tetrachlorodibenzo-p-dioxins. Table 1 also includes a number of compounds not listed in Appendix VIII, but included in 40 CFR 264, Appendix IX. They are listed in Table 1 of this report. Two compounds attributed to Appendix IX, Nos. 81 (2-Chloroethyl ether) and 198 (Ethyl Carbamate (?)) could not be located.

The next step was to evaluate all 442 compounds listed using the logic chart, to ensure that all HBLs and detection limits listed in Table 1 were correct. The first problem identified was apparent confusion in the use of Tables A-D of the Appendix to UIC Guidance No. 71. Tables C and D list reference doses (RfDs) and risk specific doses (RSDs) respectively. Both RfDs and RSDs are defined in terms of the quantity of toxic contaminant or carcinogen, respectively, injested daily by an adult over a 70 year life span. Both dose rates are given in units of $\mathrm{mg} \cdot \mathrm{kg}^{-1} \cdot \mathrm{day}^{-1}$. Conversion of these dose rates to concentration limits in drinking water is required before they can be compared with other HBLs. In UIC Guidance No. 71, the conversion factors are given in terms of the following equations:

$$
\begin{aligned}
& \text { Oral Adult RfD }=\frac{(\mathrm{RfD}) \times(\mathrm{BW})}{\mathrm{I}} \\
& \text { Oral Adult RSD }=(\mathrm{RSD}) \times \frac{(\mathrm{BW})}{\mathrm{I}}
\end{aligned}
$$


Table 1

Compounds not Listed in Appendix VIII.

\begin{aligned} & \hline No Common Name \\ & \hline 1 Acenaphthene \\ & 2 Acenaphthylene \\ & 4 Acetone \\ & 5 Acetophenone \\ & 24 Anthracene \\ & 50 Benzo[j]fluoranthene \\ & 53 Benzyl alcohol \\ & 54 Bis(2-chloroethoxy)methane \\ & 55 Bis(2 chloro-l-methylethyl)ether \\ & 57 B BHC, $\beta$ BHC and $\delta$ BHC \\ & 86 Chlorodibromomethane \\ & 87 Chloroethane \\ & 93 4 Chlorophenylphenylether \\ & 123 Dibenzofuran \\ & 196 Ethyl benzene \\ & 210 Fluorene \\ & 211 Fluoride \\ & 222 Heptachlorodibenzfurans \\ & 223 Heptachlorodibenzo-p-dioxins \\ & 233 2-Hexanone \\ & 242 Isophorone \\ & 275 Methyl isobutyl ketone \\ & 297 o-Nitroaniline \\ & 298 m-Nitroaniline \\ & 307 Nitroglycerin \\ & 338 Phenanthrene \\ & 339 Phenylenediamine acetate \\ & 358 Pyrene \\ & 378 Styrene \\ & 422 1,1,2 Trichloro propane \\ & 435 Vinyl acetate \\ & 440 Xylene \\ & \hline \hline\end{aligned}


where

$\mathrm{BW}=$ body weight (assume adult $=70 \mathrm{~kg}$ )

$\mathrm{I}=$ intake (assume $2 \mathrm{~L}$ of water per day for adults)

Hence the Oral Adult RfD or RSD has units of $\mathrm{mg} . \mathrm{L}^{-1}$, and is obtained by multiplying the RfD or RSD by $35 \mathrm{~kg} . \mathrm{L}^{-1}$.day

According to UIC Guidance No. 71 (p. 10), if both RfD and RSD are listed, then the lower of the two values should be chosen. In comparing Tables A, C and D, it does not appear that this procedure has been followed in the compilation of Table $A$, nor have the necessary unit corrections been made (it being assumed here that the difference between mg. $\mathrm{L}^{-1}$ and mg.kg ${ }^{-1}$ is trivial compared with other uncertainties in $\mathrm{HBL}$ estimations).

An example is given for No. 42, Benzidine:

UIC Guidance No. 71 , Table A. HBL $=7 \times 10^{-2} \mathrm{mg} \cdot \mathrm{kg}^{-1}$

C. $R f D=7 \times 10^{-2} \mathrm{mg} \cdot \mathrm{kg}^{-1} \cdot \mathrm{day}^{-1}$

D. $\mathrm{RSD}=2 \times 10^{-7} \mathrm{mg} \cdot \mathrm{kg}^{-1} \cdot$ day $^{-1}$

DSI, Inc., Table $1 \mathrm{HBL}=2 \times 10^{-7} \mathrm{mg} . \mathrm{L}^{-1}$

Note that:

- The compiler of Table A, UIC Guidance No. 71, selected RfD instead of RSD, which is the higher of the two, and did not convert to Oral Adult units as required.

- Envirotech, Inc., selected RSD, but did not convert RSD to Oral Adult RSD, and reported the value in $\mathrm{mg} . \mathrm{L}^{-1}$ instead of $\mathrm{mg} \cdot \mathrm{kg}^{-1}$.day-1.

It is clear that both UIC Guidance No. 71 and DSI, Table 1, will require revision to resolve such discrepancies.

The reviewer found numerous minor inconsistencies in the selection of detection limits, many of these apparently stemming from the use of 40 CFR 264, Appendix IX in preference to the detection limits given in the Third Edition of SW-846 methods.

The item "practical quantitation limit" (PQL) reported in 40 CFR 264, Appendix IX and the "detection limit" reported in SW-846 are not equivalent. According to Appendix IX:- 
"Practical Quantitation Limits (PQLs) are the lowest concentrations in ground waters that can be reliably determined within specified limits of precision and accuracy by the indicated methods under routine laboratory operating conditions ... PQLs are not part of the regulation"

In the analytical methods described in SW-846, and attached to the Envirocorp Project No. 10-1962 report, PQLs are calculated by multiplying the method detection limit by a factor, usually 10 for ground waters. The final PQL value reported in Appendix IX, rounded up to the nearest signiticant single number, should therefore be ten times the detection limit. But in some cases the PQL reported in Appendix IX for a substance is less than the detection limit, e.g., see Nos. 6, 18, 19, 27, 175, 207, 208, 230, $241,244,245,260,315,336$ and 435. In the preamble to 40 CFR Parts 124, 144, 146 and 148, the Environmental Protection Agency (Federal Register, v. 53, no. 143, July 16, 1988 , p. 28123) believes that detection limits form an appropriate basis as a surrogate for HBLs. No reference is made to PQLs. Therefore Appendix IX PQLs should not have been used for analytical detection limits of compounds listed in 40 CFR 261 Appendix VIII. If the PQL is less than the detection limit given in SW-846, DSI is presumably free to quote the PQL to ensure a conservative interpretation in the absence of a defined $\mathrm{HBL}$, but such usage would be inconsistent with EPA guidelines and with detection limits used for other compounds.

In Table 2, a list of compounds is given where the PQL given in Table 1 has for the most part been employed as a detection limit, but where the detection limit in the SW-846 method is lower than the PQL, and should have been used in calculation of the CRF. It should be noted that for methods 8240 and 8270 , PQLs are reported instead of detection limits as are normally given for other methods.

In addition to the list of detection limits that are lower than those reported, there are a number of other cases where the detection limit given for the SW-846 analytical method is higher than that given in Table 1. In many cases, this is due to Envirotech, Inc., preferring the PQL reported in 40 CFR 264 Appendix IX. Because the choice is conservative, the reviewer has not listed them in the report. Other cases where the detection limit is higher than given in Table 1, are given in Table 3. 


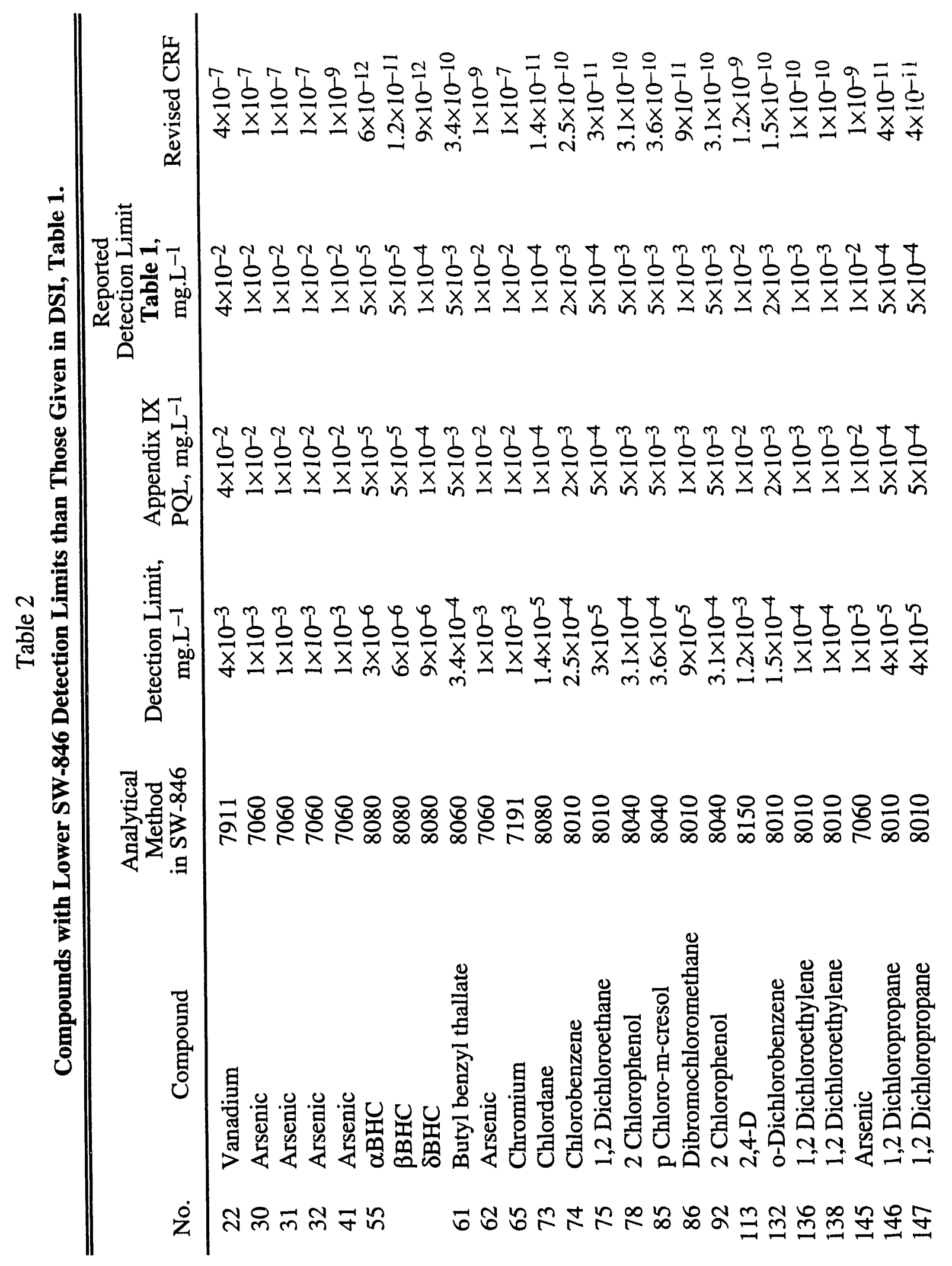




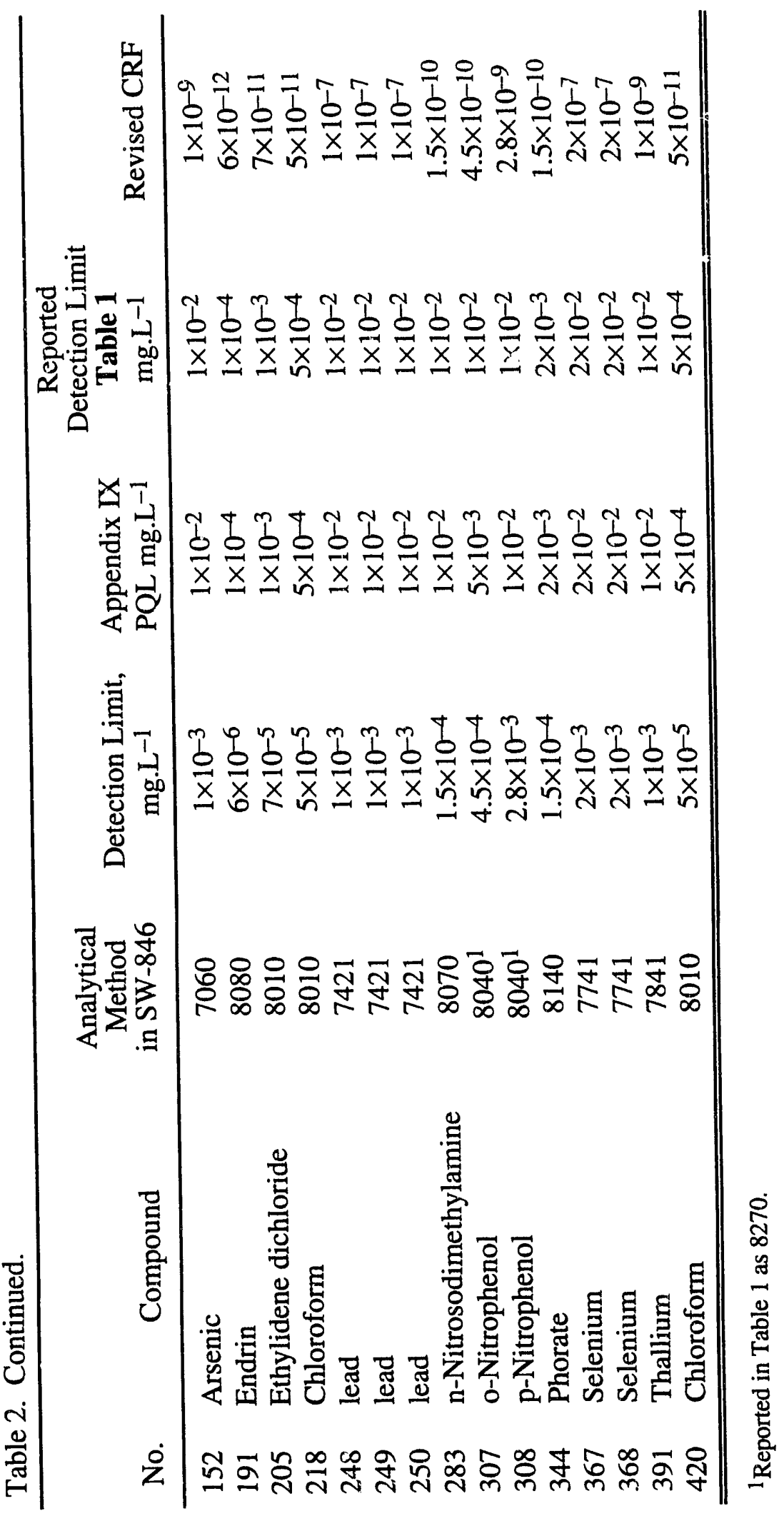


Table 3

Compounds with Higher SW-846 Detection Limits than Those Given in DSI, Table 1.

\begin{tabular}{|c|c|c|c|}
\hline No. & Common Name & Analytical Method & $\begin{array}{l}\text { Detection Limit } \\
\text { or } \mathrm{PQL}^{*}, \mathrm{mg}^{-\mathrm{L}^{-1}}\end{array}$ \\
\hline 8 & 1-Acetyl-2-thiourea & $8270-(846)$ & 1.0 \\
\hline 33 & 4,4-Oxydianiline & $8270-(846)$ & $2 \times 10^{-2}$ \\
\hline 49 & Benzyl chloride & $8240-(846)$ & 0.1 \\
\hline 88 & 2-Chloroethyl vinyl ether & $8240-(846)$ & $1 \times 10^{-2}$ \\
\hline 94 & 1-Acetyl thiourea & $8270-(846)$ & 1.0 \\
\hline 107 & Acetonitrile & 8240-III & 0.1 \\
\hline 111 & Octamethyl pyrophosphoramine & $8270-(846)$ & 0.2 \\
\hline 164 & 3,3'-dimethoxybenzidine & $8270-(846)$ & 0.1 \\
\hline 194 & Ethyl carbamate & $8270-(846)$ & $5 \times 10^{-2}$ \\
\hline 195 & Proprionitrile & $8240-\mathrm{IX}^{1}$ & 0.1 \\
\hline 232 & Hexamethyl prosphoramide & $8270-(846)$ & $2 \times 10^{-2}$ \\
\hline 277 & See 195 & & \\
\hline 281 & Propylthiouracil & $8270-(846)$ & 0.1 \\
\hline 294 & Nicotine & $8270-(846)$ & $2 \times 10^{-2}$ \\
\hline 342 & Methylene chloride & $8010-\mathrm{IX}^{1}$ & - \\
\hline 361 & Resorcinol & $8270-(846)$ & 0.1 \\
\hline 375 & $\mathrm{~N}$-Nitrosodimethylamine & $8070-(846)^{3}$ & $1.5 \times 10^{-4}$ \\
\hline 389 & Tetra ethyl pyrophosphate & $8270-(846)$ & $4 \times 10^{-2}$ \\
\hline 403 & Thiophenol & $8270-(846)$ & $2 \times 10^{-2}$ \\
\hline 431 & Tris(2,3-dibromopropyl)phosphate & $8270-(846)$ & 0.2 \\
\hline 433 & Propylthiouracil & $8270-(846)$ & 0.1 \\
\hline
\end{tabular}

*PQLs given for methods 8240 and 8270 .

${ }^{1}$ Neither PQL nor detection limit given correctly or PQL only available and reported incorrectly.

${ }^{2}$ Method 8270 cited in Table 1.

${ }^{3}$ Appendix IX given 8270 and $1 \times 10^{-2}$. 
There are a few minor typographical errors and inconsistencies in DSI, Table 1. They are listed numerically as follows:

sp. N-Nitrosopyrrolidine

should be p-Dimethylominoazobenzene

Benzo[k]fluoranthene detection limit is given in SW-846, Method 8310. Therefore a reference molecule is not required.

$2,2^{\prime}$ dichloroisopropyl ether was not found listed in 8270 or Appendix IX. Was bis(2-chloroisopropyl)ether used instead? $\triangle \mathrm{BHC}$ should be $\delta \mathrm{BHC}$ for consistency

sp. Carbon oxyfluoride Chloroethane is not listed in Appendix IX

4,6-dinitro-o-cresol (4,6-dinitro-2methyl phenol) should be a reference molecule to 2-Cyclohexyl-4,6-dinitrophenol

$$
\text { sp. 2,4-D }
$$

sp. 1,4-Naphthoquinone

small 'o' needed

Diethyl sulfate not listed under SW-846, Method 8250

sp. m-Dinitrobenzene

sp. Ethyl carbamate

1,4 Difluorobenzene not listed in SW-846, Method 8240

sp. Chloracetaldehyde

Propionitrile should be listed as a reference molecule

sp. See 114

2-Nitropropane should be listed as a reference molecule

Osmium should be listed as a reference molecule

Methylene chloride detection limit not given in SW-846, Method 8010

1,3 dichloropropylene CIS form listed in Appendix IX

$8010 \quad 2 \times 10^{-2} \mathrm{mg} . \mathrm{L}^{-1}$

$82405 \times 10^{-3}$

Which is it? trans or cis?

362,363 Safrole should be listed as a reference molecule

426 Substance is not in Appendix IX

In general, the approach taken by Envirotech, Inc. in identifying HBLs (or HBL surrogates) for all compounds listed in 40 CFR 261 Appendix VIII is logical and systematic. Apart from the discrepancies noted above, the methods used, if consistently 
followed, should result in EPA's rules and regulations being followed. There are, however, two minor issues that should be resolved if the approach adopted by Envirotech is to be incorporated in an expanded and revised issue of UIC Guidance No. 71.

1. Envirotech assumed that all compounds listed in both 40 CFR 261 Appendix VIII and 40 CFR 264 Appendix IX should be listed in Table I. This implies that neither appendix is authoritative. Is this EPA's intent with respect to UIC regulations?

2. Because 40 CFR 264 Appendix IX lists PQLs, it should not be the primary source for identifying detection limits of hazardous substances. Indeed, footnote 1 to this Appendix points out that the methods and PQLs listed are for informational purposes only. Furthermore, it is not clear whether the source of the PQLs in Appendix IX is the Third Edition of SW-846. Because the analytical methods given in SW-846 are subject to revision, and new analytical methods with superior detection limits might be developed, it is important to establish a uniform procedure for identifying detection limits for those substances for which a HBL has not been established. The reviewer recommends that the detection limits given for substances in the analytical methods in SW-846 take precedence over the PQLs in Appendix IX, even when detection limits are higher. Furthermore, SW-846 should always list detection limits and not PQLS. The revision number of the analytical method cited should also be specified, e.g., 8010(1) would refer to the first revision of method 8010. In this way, the detection limit for each compound would be traceable and up datable as improved analytical methods become available. In the event that a detection limit for a compound has not been established, then the mean detection limit for the most appropriate analytical method could be used, indicated perhaps with some symbol, e.g., $8010(1)^{*}$ where $*$ indicates the average value.

\section{Relationship between HBL and CRF}

As noted above, the $\mathrm{CRF}$ is determined by dividing $\mathrm{C}_{\mathrm{HBL}}$ by $\mathrm{C}_{0}$, the maximum average wellhead concentration. At the DSI site under consideration, it is assumed that a minimum CRF of $7 \times 10^{-11}$ is achievable. The reviewer cannot establish, from the available information. whether this CRF can be achieved at the site in question. From the petitioner's viewpoint, it is obviously desirable to raise $\mathrm{C}_{\mathrm{o}}$ to as high a value as is possible within the $C R F$ constraint of $7 \times 10^{-11}$. Hence, many compounds are assigned $C_{o}$ of $10^{6} \mathrm{mg} . \mathrm{L}^{-1}$ (or 100 percent) which is unrealistic or extremely unlikely to occur in practice. Although CRFs less than $7 \times 10^{-11}$ are not modeled, 3 substances have CRFs less than this value (Acrylamide, $9 \times 10^{-11}$; Chloromethyl methyl ether, $8 \times 10^{-11}$; Heptachlor, $\left.8 \times 10^{-11}\right)$. It is presumed that, as the $\mathrm{HBL}$ is progressively lowered, a stage will be encountered where $C_{0}$ must also be lowered to ensure that $C R F \geq 7 \times 10^{-11}$. This 
seems to be the general criterion for establishing $\mathrm{C}_{\mathrm{o}}<10^{-6} \mathrm{mg} \cdot \mathrm{L}^{-1}$, although other constraints might also apply.

Because the detection limits for a number of compounds are lower than cited in Table 1, revised CRFs were calculated and listed for those compounds in Table 2. Four compounds have revised CRFs $<7 \times 10^{-11}$, e.g. Nos 55 ( $\left.\alpha, \delta B H C\right), 85,191$, which will probably necessitate a corresponding reduction in $C_{0}$, to bring the CRF up to $7 \times 10^{-11}$.

The reviewer is unclear as to the value in computing CRFs when $\mathrm{C}_{0}$ of a substance is arbitrarily set to a value that bears little relation to the operating waste stream concentration. Presumably, an insoluble compound with a $\mathrm{C}_{0}=10^{6} \mathrm{mg} . \mathrm{L}^{-1}$, e.g., 2 Acetylaminofluorene, would be injected as a suspension in the waste stream, and would be filtered out in the injection zone. Such a scenario makes the calculation of a CRF a questionable endeavor in this case. It would be preferable to see listed $\mathrm{C}_{\mathrm{o}}$ values that are realistic, in order that the $\mathrm{CRF}$ becomes a meaningful target.

\section{Validity of "Reference Molecules"}

Envirotech, Inc., when they found a listed organic compound for which no analytical method was identified, substituted a compound that was structurally similar and possessed some or all of the functional groups of the subject, but for which an analytical method and a detection limit could be specified. For inorganic compounds, or organic compounds with attached inorganic functional groups, the detection limit of the principal element present was substituted. The substitute is referred to as a "reference molecule." A preferable term would be "surrogate substance," because the substance stands in for or proxies for the subject material. A careful review of reference molecules indicates that the selections are in most cases appropriate, and that EPA regulations are not subverted by this approach.

With respect to inorganic species, i.e., $\mathrm{Va}, \mathrm{As}, \mathrm{Cr}, \mathrm{Pb}, \mathrm{Hg}, \mathrm{Ni}, \mathrm{Os}$, $\mathrm{Se}$, the "reference molecules" are hardly substitutes, because analyses of the metals listed would be, in any case, part of any procedure to measure the concentration of the compound containing them, and therefore the selection of a "reference molecule" is in this case merely provides a means of identifying the analytical method for the element in question. It should be noted, however, that the toxicity of some elements varies with oxidation state, e.g., $\mathrm{Cr}(\mathrm{VI})$ c.f., $\mathrm{Cr}$ (III). Furthermore, an organometallic compound would be toxic, not only due to the inorganic component but also to the organic functional group(s),

For organic substances, the choice of reference molecule is in several instances more subjective. In some cases, the selected reference molecule is merely an isomer of the 
substance, e.g., No. 92. In others the reference molecule is representative of a class of compounds with similar chemistry and molecular weight, e.g., No. 81 or 85 . In some, e.g., No. 107, where acetonitrile proxies for cyanogen bromide, the substitution is not particularly close. For the most part, however, the selection of a "reference molecule" is appropriate, and the detection limit so obtained is referenced to the analytical method that would probably be used to quantify the concentration of the subject compound. However, care should always be taken that the selected molecule is structurally similar, contains similar or identical functional groups, and displays similar systemic or carcinogenic toxicity.

The reviewer raises the question as to whether the "reference molecule" approach is the most elegant way of dealing with the problem. If, for example, an organic compound belongs to a class of compounds, e.g., chlorinated hydrocarbons, then surely the selection of a specific reference molecule belonging to that class for which a detection limit is given under Method 8120 will not normally result in a more accurate estimate of the detection limit for the hazardous compound than if the average detection limit for that method were chosen instead?

Envirotech, Inc. restricted their search of detection limit data, only to the analytical methods given in SW-846. If the hazardous compound is listed in 40 CFR 261, Appendix VIII and/or in 40 CFR 264 Appendix IX, then it would be surprising if no data is available in the literature on analytical methods and detection limits for that compound. Would sources other than SW-846 prove to be acceptable in specifying detection limits for come compounds? Would sources from the refereed literature, if properly documented, be as satisfactory as the selection of methods using CFR 40 Part 261, Appendix III, when the detection limit of the hazardous compound is not reported in SW 846 under the specified method?

\section{Upgrading Support Document UIC Guidance No. 71.}

The complete tabulation by DSI, Inc. of all compounds listed in 40 CFR 261 Appendix VIII and 40 CFR 264 Appendix IX is a valuable exercise and demonstrates the possibility of revising UIC Guidance No. 71 in a similar manner. As noted in a preceding section, there appear to be some inconsistencies in the tabulations provided in the appendix to UIC Guidance No. 71, and the document could also be improved by better referencing and traceability of cited data for which HBLs were derived. Because UIC Guidance No. 71 is intended to be a practical guide to petitioners, it should be formatted so that pertinent information can be directly accessed. In any revised version, emphasis 


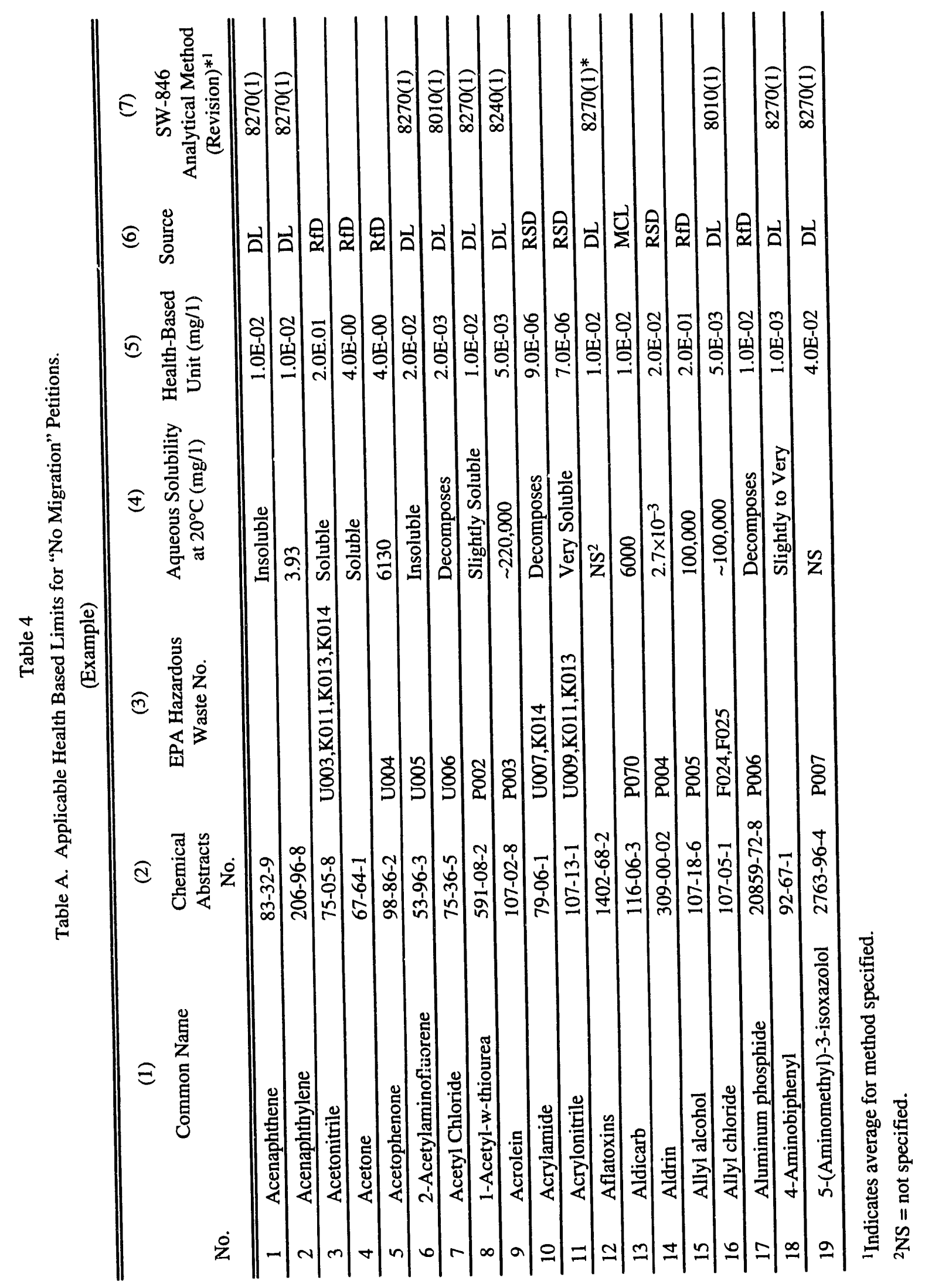


should be placed on updating and restructuring Table $A$ as the primary source of information on HBLs. If Table $A$ is comprehensively revised and periodically updated there would be no need for the petitioner to search anywhere else for information, and Tables B, C and D could be eliminated.

Table A could be expanded to include information conveniently included in Table 1 of the DSI, Inc. submission. Table 4 is a mockup of a proposed format. Comments on the layout follow.

- The No. column, giving the number of each substance is probably unnecessary, and would make renumbering necessary if additional compounds were to be incorporated at a later date. A decision should be made whether to incorporate all compounds listed in both 40 CFR 261 Appendix VIII and 40 CFR 264 Appendix IX.

- The first column, "Common Name" gives the common name of all compounds. The use of names, based on IUPAC conventions, could cause confusion, but could be included in parentheses, when compounds are identified using the IUPAC convention in SW-846.

- Column 2, the "Chemical Abstracts No.," would eliminate any possible ambiguity. Furthermore, the use of Column 2, obviates the need for rigorous names based on IUPAC conventions, which in the case of some pesticides, would fill up space unnecessarily.

- Column 3, giving the "EPA Hazardous Waste No." is a useful cross reference.

- The solubility of a given compound given in Column 4 should be specified with respect to pure water. Naturally, the solubility will vary, depending on the presence of complexants, acids, and dissolved salts. The DSI, Table 1 solubility listings appear to be rather superficial. Various compilations are available that could yield superior information. Sources should be referenced with superscripts and footnotes.

- Column 5, the HBLs should be presented in a uniform manner, e.g., 4.0E-04 (mg. $\mathrm{L}^{-1}$ ), and calculated from RfDs and RSDs, as necessary using a $70 \mathrm{~kg}$ man and 2 L.day $^{-1}$ water consumption. By incorporating all HBLs in this table, UIC Guidance No. 71 Tables B, C and D are rendered superfluous. It might be preferable to specify HBLs in $\mu \mathrm{g} . \mathrm{L}^{-1}$ to eliminate the need for exponents.

- Column 6 indicates the sources of the HBLs. All primary sources should be referenced. In this column, DL signifies that a detection limit was employed, which implies that an entry is required in Column 7. 
- Column 7 gives the most sensitive analytical method for the compound in SW-846, and the revision number. An asterik indicates that the average [lowest?] detection limit for that method is cited. The use of an average [lowest?] detection limit for that method obviates the need for "reference molecules," and makes it easier to update the table as new information becomes available.

\section{Computer Model Applications}

The application of computer modeling to the database compiled by Envirotech, Inc. as Table 1 or as Table $\mathrm{A}$ in a revised version of UIC Guidance No. 71 is at present limited. The proposed tabulation, Table 4, could be incorporated in a spreadsheet or a personal computer using Excel or Lotus 123 and expanded to incorporate other information, such as decomposition rate constants, adsorption coefficients octanol/water coefficients etc. and used to calculate the CRF for all compounds given whatever site constraints the investigator chooses.

Taking a longer view, the database could be greatly expanded with additional column entries to incorporate all relevant thermodynamic and kinetic data for the listed compounds, as may already be partially available in the CHEMFATE and Arizona databases. If such a database were carefully constructed, it could be used as input for computer models written to simulate the behavior of hazardous constituents in the injection zone.

\section{Conclusions and Recommendations}

The following conclusions were reached during the evaluation of DSI's Table 1.

1. The proposed methods for assigning HBL's to hazardous waste compounds in 40 CFR 261, Appendix VIII and 40 CFR 264, Appendix IX are generally satisfactory, although inconsistancies in the use of PQLs and detection limits by Envirocorp, Inc. and inconsistent use of RfDs and RSDs in UIC Guidance No. 71 will necessitate revision of Table 1 .

2. Although DSI's calculation of CRFs was correct, $\mathrm{C}_{\mathrm{o}}$ was usually assigned arbitrarily, and apparently bears little relation to hazardous waste concentrations that will be injected. It is not possible with available data to establish whether the minimum CRF, $7 \times 10^{-11}$, is meaningful.

3. The use of "reference molecules" is a valid concept, provided that, for organic compounds, the substitute molecule is structurally similar and behaves similarly or contains functional groups that show similar systemic or carcinogenic properties to 
the molecule being substituted. It is however, not clear whether the use of a reference molecule is any improvement over the use of an average [lowest?] detection limit for the analytical method that would be used to measure the concentration of the hazardous organic substance.

4. The general approach taken by DSI would be useful in updating and revising UIC Guidance No. 71.

5. The application of computer model simulations to complex and varied organic and inorganic mixes of compounds if they were injected is presently limited, but the incorporation of the Table 1 format in a spread sheet would be useful in the preparation of petitions

The following recommendations are made:

1. Resolve the question whether 40 CFR 261 Appendix VIII and/or 40 CFR 264, Appendix IX hazardous constitutes should be considered as hazardous wastes under 40 CFR 148 (perhaps this is clear somewhere in the Regulations).

2. Have DSI revise Table 1 to eliminate errors and inconsistencies noted in this report. The use of PQLs in 40 CFR 264, Appendix IX and SW-846 should not be used in preference to detection limits in SW-846.

3. Update and revise of UIC Guidance No. 71 with improvements and simplifications suggested in the text. Full traceability of all data used should be possible. A floppy containing Table $\mathrm{A}$ as a spreadsheet should be placed in a pocket in the revised version of UIC Guidance No. 71, if funds permit. 

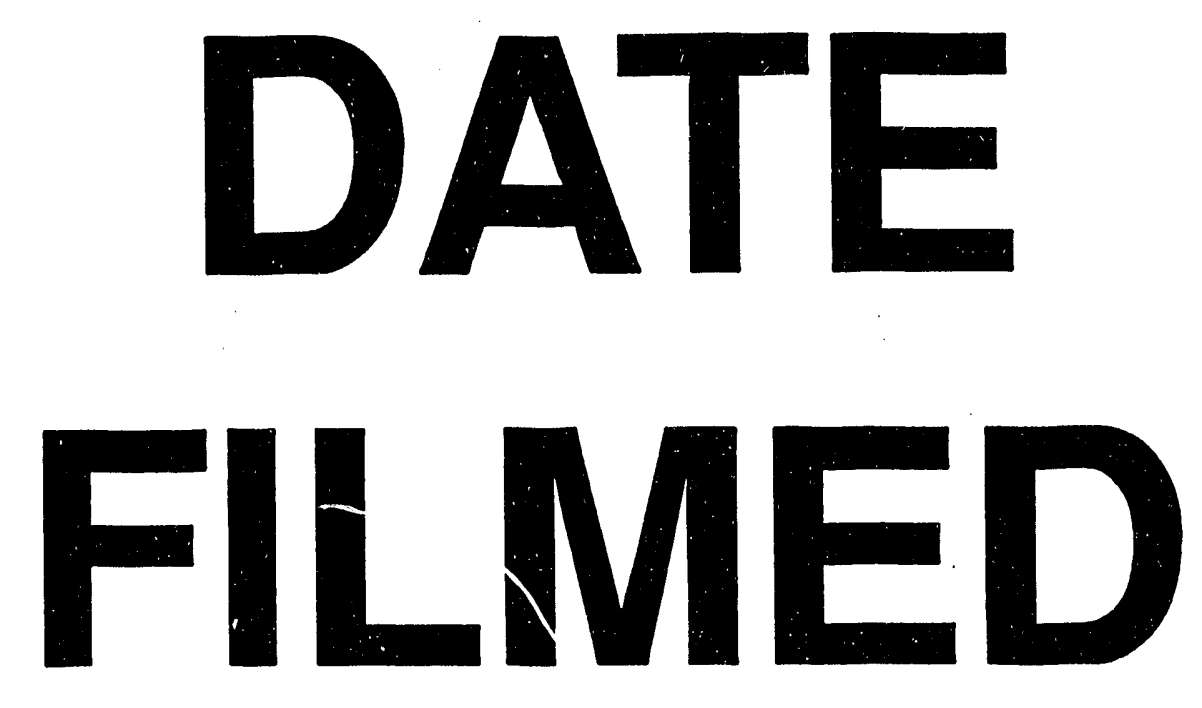

$8 / 19 / 93$
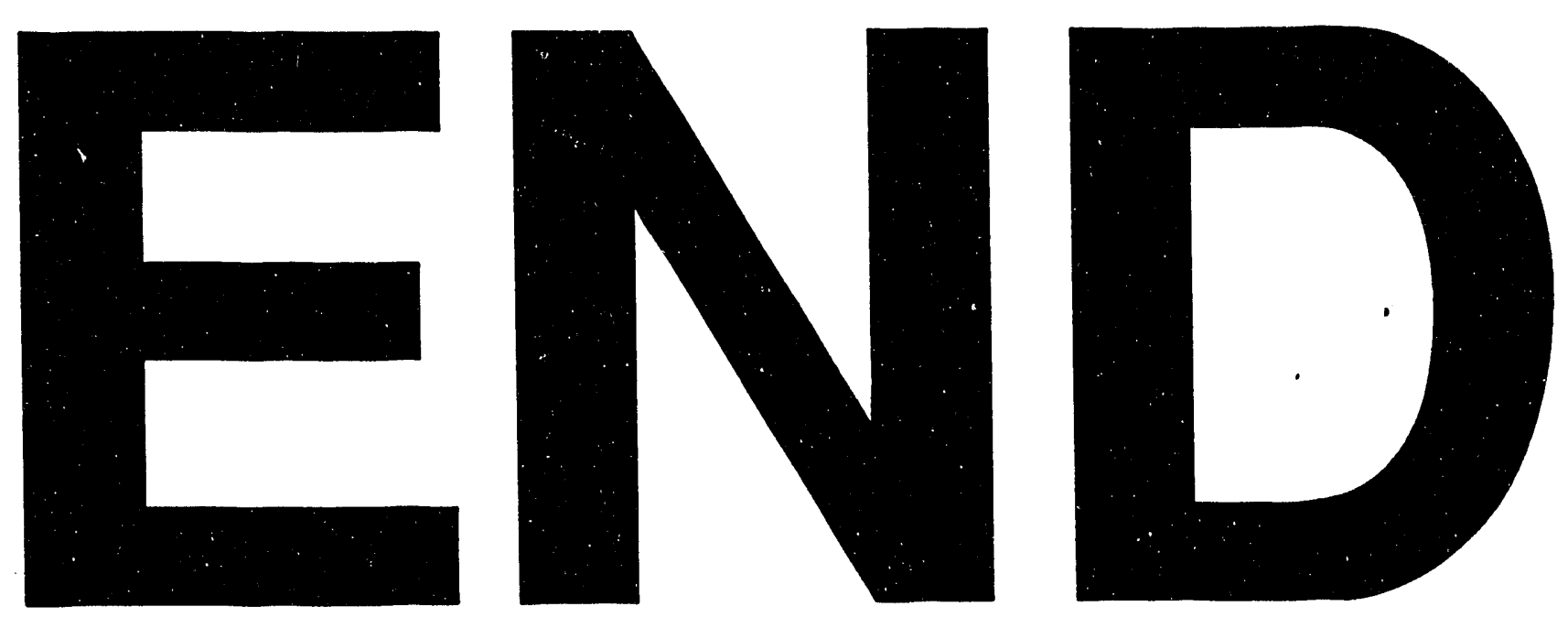
